\title{
A review of the economic impact of high levels of variance in fertiliser spreading systems
}

\author{
M.C.E. GRAFTON ${ }^{1}$, I.J. YULE² and M.J. MANNING ${ }^{1}$ \\ ${ }^{1}$ Ravensdown Fertiliser Co-operative Ltd., Christchurch, New Zealand, \\ ${ }^{2}$ New Zealand Centre for Precision Agriculture, Institute of Agriculture and Environment, Massey University, \\ Palmerston North, New Zealand. \\ Miles.Grafton@ravensdown.co.nz
}

\begin{abstract}
Recent technological improvements in Geographical Information Systems (GIS) have made it possible to measure the accuracy of fertiliser spreading in the field. This demonstrates that the field coefficient of variation, "field CV", of actual spread patterns on farms is significantly higher than appreciated by most end users and service providers. Levels of field CV greater than $40 \%$ for spreading $\mathrm{N}$ fertiliser produces a $20 \%$ yield reduction, which in terms of urea on dairy pasture is potentially around $\$ 170$ million nationally, and is economically significant. Manufacturers of fertiliser spreading equipment and ground-spread applicators have introduced improved delivery technologies which reduce field CV. Mostly these improvements relate to GPS use to assist drivers, automated maintenance of bout width, control of product flow and provision of automatic start-stop control. These improvements have the potential to reduce $\mathrm{CV}$ to $20 \%$ and reduce economic loss to $3 \%$. Similarly, combinations of GIS methods and differential global positioning systems (DGPS) will assist pilots to reduce field CV from $70 \%$ to $40 \%$.
\end{abstract}

Keywords: Geographic Information Systems, coefficient of variation, fertiliser spreading accuracy, real time kinematic, spread pattern.

\section{Introduction}

This paper reviews the economic impact of spreading accuracy. Ground spreaders have been developing for about 100 years, since the Haber process for synthesising ammonia. Twin disc ground-spreaders, which dominate ground based fertiliser application, and aerial application have developed since the Second World War.

Spreading standards which are used to establish the correct bout width so that the pattern overlap provides an acceptable spread were established in 1984 with ISO 5690-1 and ISO 5690-2, which form the basis of most spreading standards throughout the world, including the New Zealand Spreadmark ${ }^{\circledR}$ standard for both ground and aerial operators. It is this standard which details how transverse fertiliser spread pattern should be measured, which provides the transverse coefficient of variation (CV). Søgaard \& Kierkegaard (1994) established the theory of exponential increases in cost, in terms of reduced fertiliser efficacy and spreading accuracy within a field crop or paddock with reduced spreading accuracy, which is referred to today as the field CV.

There is confusion as to what a $\mathrm{CV}$ (the ratio of the standard deviation to the mean) means in fertiliser spread. Some of the confusion is a result of there being two commonly used terms when discussing fertiliser $\mathrm{CV}$, i.e., "transverse CV" and "field CV". The most commonly measured transverse $\mathrm{CV}$ is produced from a transverse tray test and is used to calculate the appropriate bout or swath width for a spreading vehicle or aircraft to produce an acceptable overlapping spread pattern. The field $\mathrm{CV}$, that is the actual $\mathrm{CV}$ achieved in the field, is of economic importance and reflects the additional effects of inaccurate driving, incorrect starting and stopping positions and the effect of field shape. It is the variation in spread achieved over the paddock. This is derived from knowing the spread footprint of the spreader and using Real Time Kinematic (RTK) differential global positioning systems (DGPS) tracking to simulate the position of fertiliser application from the location, bearing and speed of the vehicle (Lawrence \& Yule 2007a). The New Zealand Spreadmark ${ }^{\circledR}$ standard specifies a transverse pattern test $\mathrm{CV}$ of $15 \%$ for nitrogenous fertilisers and $25 \%$ for other fertilisers and lime. These values are chosen as they are considered the trigger point where the spreading accuracy is seen as being economically significant (ISO 5690-2). Spreadmark patterns are calculated from a transverse spreading test method requiring the fertiliser spreading vehicle or aircraft to pass over a continuous row of sixty $0.5 \mathrm{~m} \times 0.5 \mathrm{~m}$ trays at a typical application speed with a typical application rate. The bout width is calculated so the pattern overlap produces the required $\mathrm{CV}$ at that application rate and speed.

The pattern test is the starting point, or the minimum possible $\mathrm{CV}$ achievable. However, factors such as driving error, terrain, speed changes which affect the application rate, areas where imperfect overlap or no 


\section{Relationship of Cost with Increasing CV on Urea Spread on Dairy Flats}

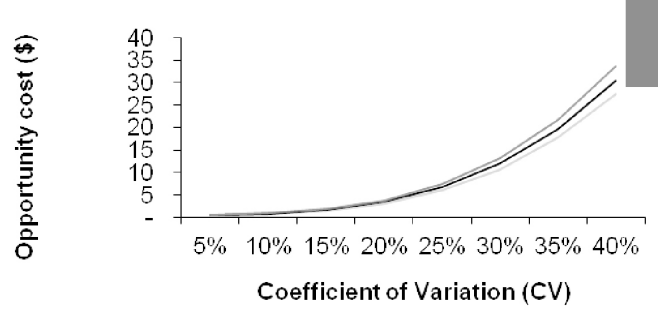

Milk Solids Payout $\$ 6.50$-Milk Soilds Payout $\$ 7.25$

Figure 1: Relationship of cost with increasing CV on New Zealand dairy pasture applying urea. From Grafton et al. (2011a)

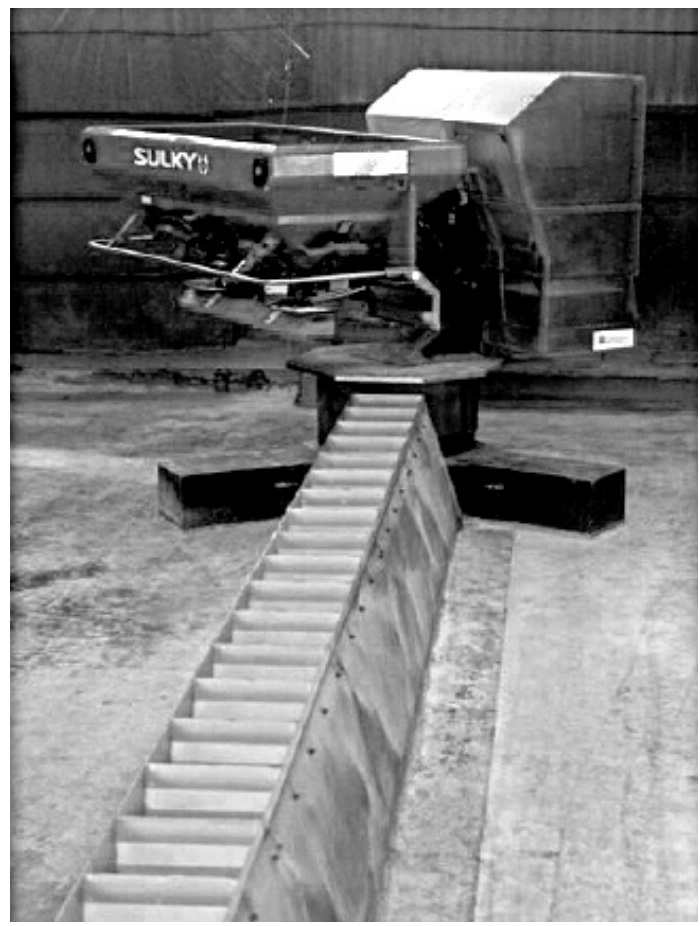

Figure 2 The CEMAGREF CEMIB automatic testing device. Reproduced from Piron et al. (2010).

overlap occurs and product variation all combine to increase field CV (Lawrence 2007; Lawrence \& Yule 2007a,b; Grafton et al. 2011a; Murray et al. 2007; Yule \& Grafton 2010; Yule 2011). Field CV for spreading trucks is around $40 \%$ (Lawrence \& Yule. 2007a), and for aircraft around 70\% (Grafton et al. 2011b; Murray et al. 2007; Yule et al. 2008).

For examples of the impact of field $\mathrm{CV}$ and its economic importance as the cost in terms of loss of fertiliser response, for all products increase

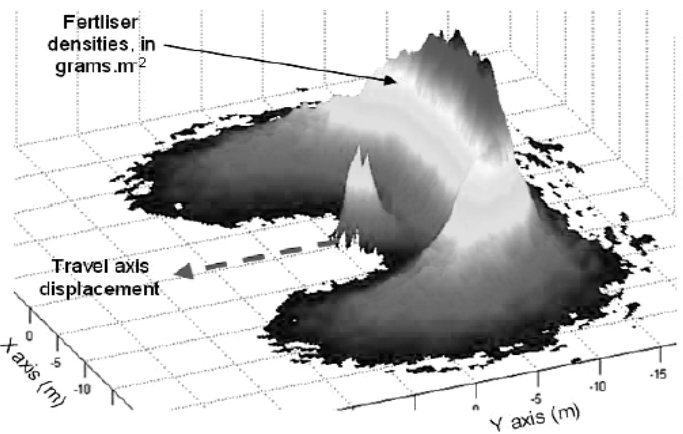

Figure 3 The three dimensional spreader pattern developed from the device shown in Figure 2. Reproduced from Piron et al. (2010).

exponentially with CV see: Søgaard \& Kierkegaard (1994), Lawrence (2007), Lawrence \& Yule (2007a), Miller et al. (2009), Grafton et al. (2011a), and Forristal (2012). Figure 1 shows the impact of increasing field $\mathrm{CV}$ on New Zealand dairy pasture.

In Europe facilities exist which automatically test fertiliser delivery systems and provide computerised measurement of spreading devices. These produce a three dimensional spread pattern test within a few seconds (see Figures 2 and 3).

This device rotates the spreader over collectors on load cells, from which a three dimensional spreader footprint is developed by proprietary software for the products being tested.

Spreaders are tested over a range of products and size distributions, so comparisons can be made, as the rapid testing allows 120 tests to be undertaken per day. Thus spreaders can be tested and settings found for a range of products; this is a spreader "type test" which replaces the transverse tests over collectors. Many of the spreaders tested using these facilities are being used by arable farmers in New Zealand. As these sophisticated testing systems are unavailable in New Zealand, only those products tested in these facilities are calibrated.

The spreaders use bulk density tests and fertiliser size guides as determined by a sieve box to obtain the correct settings to achieve the best bout width. European spreader manufacturers such as Amazone possess automatic testing devices and use these facilities in spreader development. They have also undertaken field trials to measure the effects of field $\mathrm{CV}$ on crop yields which has confirmed the exponential impact on cost, based on yield suppression. Striping is only visible if field CV is greater than $40 \%$, when yield is suppressed by around $20 \%$, and at $50 \%$ there is a $30 \%$ reduction (Mersmann et al. 2013).

Some new models are able to spread over wide bout widths, $30 \mathrm{~m}$ plus, and there have been complaints of striping by farmers spreading fertiliser blends recommended by their farm advisers. This is indicative 
of blends splitting at wide bout widths, as striping is not visible at narrower bout widths. Therefore, only homogenous products are suitable for spreading at wide bout widths from these machines. This is because the drag coefficient of particles in ballistic modelling reduces the speed of particles. Particles which are dense, large and spherical have a low drag coefficient, in that order of importance. The degree of drag is directly proportional to the square of particle velocity. The faster fertilisers are spread the greater the drag and the more blended fertilisers split. Miserque et al. (2008) demonstrated this to hold true for blends in a comprehensive case study. In addition, if air density changes or wind increases, thus altering the environmental spreading conditions, this has more effect at higher particle velocities. This may cost the farmer who will have reduced fertiliser efficacy from uneven spread.

\section{Problem: a divergence of views}

Ground and aerial applicators have been vociferous in their opinion, both publically and at the Fertiliser Quality Council forum, that the variation in physical quality of the product supplied by fertiliser companies, especially superphosphate, is the limiting factor to improved spread. The fertiliser manufacturers have accepted that their product varies, but have the view that spreader operators need to address factors within their control which have far more influence on in-field CV.

New Zealand spreader operators have a narrow range of test results generated from pattern tests. Testing is time-consuming, and type testing spreaders over a wide range of particle size distributions and products is financially difficult. The cost of data collection limits the assessment of in-field spreading accuracy, which has only been undertaken in detail for urea by Lawrence (2007). Superphosphate and urea are the major products applied, and customers have little idea of spread quality supplied, taken in this context to be the field CV.

As New Zealand spreaders have not been "type tested", an issue exists when the characteristics of the product changes from that tested. Operators do not have the information to properly adjust equipment as particle size distribution and uniformity change. However, as long as no more than $15 \%$ of the product is in the Spreadmark sieve box pan then variation in superphosphate should not affect field CV by more than 5\% (Yule 2011). European spreaders are type tested and have tables to adjust settings based on particle size and uniformity to attain optimum spread. Most New Zealand spreaders do not have this information for settings, and if altered are changed subjectively (Yule \& Grafton 2013).
New Zealand spreaders are commonly general purpose and used to potentially apply a range of materials. However, only three products, urea and any two commonly spread products used from the spreader by the operator, are tested for Spreadmark certification. Only about $25 \%$ of New Zealand operators are certified.

\section{Hierarchical Potential Costs associated with poor field $\mathrm{CV}$}

\section{Aerial spreading}

In hill country, which is often deficient in all or some of the nutrients sulphur (S), phosphorus $(\mathrm{P})$, nitrogen (N) and potassium (K) (Hedley et al. 2011), costs of inaccurate spreading are difficult to measure. Murray et al. (2007) and Yule et al. (2008) found that the CV of aerial topdressing was over $70 \%$. Yule \& Grafton (2010) and Grafton et al. (2010) established reasons which contribute to spread variation, whilst Gillingham \& Metherell (2005) undertook desktop exercises which calculated the effects of inaccurate bout width flying at constant speed. Some actual contributing elements to field $\mathrm{CV}$ are flow control to maintain application rate, achieving target transverse CV (bout width), starting and stopping positions and distance from airstrip. This last contributor may be driven by the fact that areas furthest from the airstrip are more expensive to apply fertiliser to than those adjacent to the strips. For example, Olsen P tests taken on a large 4000 ha hill country property in the lower North Island in the early 2000s found variation in Olsen P between 3 and 75, and on a smaller properties (ca. 1500 ha) Olsen P values between 8 and 32 (Ants Roberts Chief Scientific Officer, Ravensdown pers.comm 2011 ) .

Information such as this suggests that blanket applications of single superphosphate over 50 years have not been random, as the higher Olsen $\mathrm{P}$ levels were close to the airstrip and the low Olsen P levels were distant from the strip. This increases spread variability as the rate applied differs dependent on location and distance from the airstrip. This information changed the behaviour of one farming group to move from blanket to zonal topdressing.

Murray et al. (2007) and Grafton et al. (2011b) established, using Geographical Information System (GIS) software, that the cost of inaccurate spread in terms of reduced fertiliser response is greater than the application cost, based on a decision-tree mining for fertiliser responses in hill country (Zhang et al. 2004). This system uses discrete cut-off points, based on environmental influences of climate, slope, aspect and fertiliser history, to predict production from fertiliser application. Extrapolating this information to whole farm applications using RTK GPS data collection linked to hopper openings and, therefore, flow rates 
suggests the cost of inaccurate application in terms of lost fertiliser efficacy to be about $\$ 75$ tonne $^{-1}$ (Grafton et al. 2011b).

There is economic opportunity to improve technology and improve aircraft application accuracy. This will come about with the introduction of computerised delivery systems, using pre-loaded application maps for zonal topdressing. If farmers and operators better understood the economic cost of poor spread then they would value the importance of better application and the resulting improved fertiliser response. There will need to be realisation of where the true cost of aerial topdressing lies. That is in the yield of topdressing time in relationship to ferrying the aircraft to the areas being sown. On some large properties an aircraft must travel $12 \mathrm{~km}$ from the airstrip to the end of the property; this results in 6 minutes flying time there, to spread for 1.6 minutes, and take 6 minutes to return.

This knowledge should result in better decision making in terms of airstrips being used, contract prices paid and a demand for better application technology to achieve the improved response available,

\section{Ground-spread}

A method of measuring field $\mathrm{CV}$ from groundspread vehicles has been developed (Lawrence 2007; Lawrence \& Yule 2007a,b). Grafton et al. (2011a) and Yule (2011) quantified contributing factors to field CV on near flat paddocks. The largest contributing factors were track spacing, or maintaining bout width, and flow control to maintain application rate.

Although this appears to be self-evident, there is very little uptake of technologies which mitigate the issues leading to high field CV. There are only about 80 contract spreading trucks out of a fleet of 800 fitted with DGPS, flow control and automatic overlap shut down which can be preloaded with fertiliser prescription maps.

The lack of uptake is due to the inability to obtain a return from the investment in the technology. Farmers have been unwilling to accept increased charges for improved technology. The technology has largely been introduced by Ravensdown as a service to improve shareholder outcomes, and they have been willing to install, service and provide proof of placement maps to private operators wishing to lease the technology.

The benefits of improved application need to be explained and understood by farmers and their advisors.

\section{Results: financial implications}

Adopting the spreading technologies above reduces CV on flat dairy and arable situations from around 50\% (Lawrence 2007) to as low as $20 \%$. Lawrence \& Yule (2007a) established that the relationship between field $\mathrm{CV}$ and cost in dollar terms of reduced fertiliser efficacy is exponential, and this is of economic importance when CV $>30 \%$ ( see Mersmann et al. 2013; Miller et al. 2009). The importance in dairy pasture in New Zealand are shown in Figure1.

The financial impact of reducing $\mathrm{CV}$ for each urea application on New Zealand dairy pasture was described by Grafton et al. (2011a). A typical field CV of $37 \%$ produced an economic loss of $\$ 21 \mathrm{ha}^{-1}$. Reducing that field CV to $20 \%$, reduced the economic loss to $\$ 3 \mathrm{ha}^{-1}$. For ground-spread and aerial application the costs of inaccurate spread, field CV $>40 \%$ for ground and $>60 \%$ for aerial are around $\$ 13 \mathrm{ha}^{-1}$ for ground spread and $\$ 18$ $\mathrm{ha}^{-1}$ for aircraft, which are greater than the application cost.

Yule \& Grafton (2013) established the fertiliser sales mix for New Zealand dairy farms (Table 1).

The total sales mix is shown in Table 1 to demonstrate that these savings are achieved on only one of the products applied, i.e., urea; see table 2.. Urea responses are fairly immediate and are relatively cheap and easy to measure. Other fertiliser responses take much longer to occur and far fewer trials have been undertaken examining spreading accuracy and the value of the response.

Although superphosphate is also applied in the same quantity in terms of tonnes as urea, the economic implications of field CV have not been examined. Some work has been undertaken by Grafton, using the

Table 1 Sales mix of fertiliser in New Zealand by tonnes, value per cow and per hectare

\begin{tabular}{|c|c|c|c|c|}
\hline Fertiliser & $\begin{array}{r}\text { Tonnes } \\
(000)\end{array}$ & $\begin{array}{r}\text { Value NZ(\$) } \\
\text { (million) }\end{array}$ & $\begin{array}{r}\text { Value Cow }{ }^{-1} \\
\text { (\$) }\end{array}$ & $\begin{array}{r}\text { Value ha-1 } \\
\text { (\$) }\end{array}$ \\
\hline Superphosphate products & 603 & 223 & 46.31 & 134.29 \\
\hline Potassium products & 106 & 69 & 14.35 & 41.62 \\
\hline Ammonium phosphate (s) & 138 & 124 & 25.70 & 74.52 \\
\hline Urea & 604 & 449 & 93.21 & 270.30 \\
\hline Magnesium & 9 & 6 & 1.16 & 3.35 \\
\hline Total & 1,460 & 871 & 180.72 & 524.08 \\
\hline
\end{tabular}

The value of urea represents applications of $360 \mathrm{~kg} \mathrm{ha}^{-1}$, derived by dividing the value of urea spread by the cost. Number of cows farmed and hectares in dairy sales mix is extrapolated from New Zealand industry sales as proportion of market share. Assumes four applications of $90 \mathrm{~kg}$ urea ha-1, economic benefit of improved in CV (40\% to $20 \%)$. 
accepted method of overlaying a superphosphate spread pattern, using the same application rate over the vehicle track. Where patterns overlap the rate is combined and a statistical Krig analysis undertaken to calculate the CV. From the work undertaken it appears that field CV of superphosphate is between $12 \%$ and $17 \%$ higher than for urea. This probably reflects the fact that the bout width is set at a $25 \%$ transverse $\mathrm{CV}$ for non-nitrogen fertiliser, rather than $15 \%$ used for nitrogen fertiliser. Therefore, the starting point for accuracy is the main reason for a higher field $\mathrm{CV}$, and the wider bout width seems to explain the remainder of the increase, as there are larger regions where overlap does not occur, increasing field $\mathrm{CV}$ at field margins.

The greater transverse CV allowed for non-nitrogen fertiliser is probably due to the modifying effects of the residual properties of $\mathrm{P}$ already in the soil and the lack of mobility of $\mathrm{P}$ when compared with $\mathrm{N}$.

\section{Conclusions and discussion}

During the last 20 years there has been considerable work undertaken to improve ground-spreading technology. This has occurred in conjunction with improvements in GIS measurement, modelling and the increasing availability of DGPS vehicle monitoring, guidance assistance and finally GPS guided automation of control.

This contrasts with aerial applicators that still use manual systems operated by the pilot, often assisted by GPS. Murray et al. (2007) found in-field CVs greater than $70 \%$. It is likely that some inertia in improving spreading technology results from farmers and advisors assuming a perfect spread. Little inclination to improve the technology has occurred as farmers are unaware of the compelling economic argument. In addition, aerial topdressing of solids occurs in few countries. Technologies controlling flow control of liquids and GIS map transfer has been in place for some time. Liquids are the normal physical state of agricultural aircraft application in most countries. Bringing these technologies to solid application requires some capital investment as well as engineering and GIS skills, seldom held by operators of small agricultural aircraft companies.
Today many manufacturers produce spreaders with DGPS automation of spread. Operators using DGPS do not have to guess starting and stopping points as these are calculated automatically. Some machines take account of field shape, reducing spread width to prevent double spreading and border spreading where the spread is altered to offer a rapid cut off of application at the boundary. These have both benefits in producing reduced in field $\mathrm{CV}$, and can also reduce the environmental risk of fertiliser being discharged into sensitive areas. The rural sector needs to understand the financial benefits of using the technologies discussed and be prepared to increase the uptake by paying a premium to those investing in providing them.

\section{ACKNOWLEDGEMENTS}

The authors acknowledge the assistance of Ants Roberts of Ravensdown who assisted the authors in understanding the target audience and provided helpful suggestions.

\section{REFERENCES}

Anon. 2012. Situation and outlook for primary industries. Accessed 13 May 2013. http://www.MPI.govt.nz

Ball, R.; Field, T. 1982. Nitrogen Fertilisers in New Zealand agriculture Ed. Lynch, P. New Zealand Institiute of Agricultural Science. p. 63.

Forristal, D. 2012. Fertiliser spreading: getting the mechanics right. Teagasc CELUP. Oak Park Crops Research. www.teagasc.ie/publications/2012/1099/ Dermot_Forristal.pdf. Accessed 22 April 2013.

Gillingham, A.G.; Metherell, A.K. 2005. Effects of variability in fertiliser application on hillcountry pasture productivity. pp. 363- 369 In: Developments in fertiliser application technologies and nutrient management. Eds. Currie, L.D.; Hanly, J.A. Occasional Report No. 18. Fertilizer and Lime Research Centre, Massey University, Palmerston North, New Zealand.

Grafton, M.C.E.; Yule, I.J.; Lockhart J.C. 2010. An economic analysis of the topdressing industry. pp 405412. In: Farming's future: minimizing footprints and maximizing margins. Eds. Currie, L.D.; Christensen, C.L.. Occasional Report No. 23. Fertilizer and Lime

Table 2 Value to New Zealand dairy farmers by improving CV of urea spread from 40\% to 20\% Grafton et al.(2011a) and Lawrence and Yule (2007a) Ball \& Field (1982) (Anon., www.MPI.govt.nz, downloaded 13 May 2013),.

\begin{tabular}{|c|c|c|c|c|c|}
\hline $\begin{array}{l}\text { Dairy Pay Out } \\
\text { (\$) }\end{array}$ & $\begin{array}{r}\text { Economic Loss } \\
\text { CV } 40 \% \\
(\$)\end{array}$ & $\begin{array}{r}\text { Economic Loss } \\
\text { CV } 20 \% \\
\text { (\$) }\end{array}$ & $\begin{array}{r}\text { Improvement } \\
\text { (\$) ha-1 }\end{array}$ & $\begin{array}{r}\text { Total Benefit } \\
4 \text { Applications } \\
\$ \text { ha }^{-1}\end{array}$ & $\begin{array}{r}\text { Total Benefit } \\
\text { Over } 1.66 \text { million ha } \\
\text { Million (\$) }\end{array}$ \\
\hline 5.50 & 23.18 & 2.59 & 20.59 & 82.34 & 137 \\
\hline 6.00 & 25.28 & 2.83 & 22.46 & 89.83 & 149 \\
\hline 6.50 & 27.39 & 3.06 & 24.33 & 97.31 & 162 \\
\hline 7.00 & 29.50 & 3.30 & 26.20 & 104.80 & 174 \\
\hline
\end{tabular}

Savings derived for urea, $\mathrm{N}$ responses based on conversion ratio of $15 \mathrm{~kg}$ dry matter per $\mathrm{kg}$ milk solids. 
Research Centre, Massey University, Palmerston North, New Zealand: ISSN 0112-9902.

Grafton, M.C.E.; Yule, I.J.; Rendle, B.W. 2011a. A review of technologies for improved fertiliser application accuracy. 7 pages. In: Adding to the knowledge base for the nutrient manager. Eds. Currie. L.D.; Christensen. C.L. Occasional Report No. 24. Fertilizer and Lime Research Centre, Massey University, Palmerston North, New Zealand: ISSN 0112-9902.

Grafton, M.C.E.; Yule, I.J.; Manning, M.J. 2011b. Analysis of material flow from topdressing aircraft.14 pp. In: Adding to the knowledge base for the nutrient manager. Eds. Currie. L.D.; Christensen.C.L. Occasional Report No. 24. Fertilizer and Lime Research Centre, Massey University, Palmerston North, New Zealand: ISSN 0112-9902.

Hedley, M.J.; Furness, H.; Fick, J. 2011. Outlook for long-term fertilizer demand on aspects of organic $\mathrm{P}$ re-cycling in New Zealand. $12 \mathrm{pp}$. In: Adding to the knowledge base for the nutrient manager. Eds. Currie, L.D.; Christensen, C.L. Occasional Report No. 24. Fertilizer and Lime Research Centre, Massey University, Palmerston North, New Zealand: ISSN 0112-9902.

ISO 5690-2. 1984. Equipment for the distribution of fertilisers. International Organization for Standardization, Geneva.

Lawrence, H.G. 2007. Adoption of precision agriculture technologies for fertiliser placement in New Zealand. $\mathrm{PhD}$ thesis. Massey University.

Lawrence, H.G.; Yule, I.J. 2007a. Estimation of the infield variation in fertiliser application. New Zealand Journal of Agriculture Research 50: 25-32

Lawrence, H.G.; Yule, I.J. 2007b. Application modelling of ground based spreading vehicles. pp. 306-311. In: Critical aspects of soil and water management. Eds. Currie, L.D.; Yates, L.J. Occasional Report No. 20. Fertilizer and Lime Research Centre, Massey University, Palmerston North, New Zealand: ISSN 0112-9902.

Mersmann, M.; Walthers, S.; Sia T. 2013. Fertilizer application - driving the future with innovations. $13 \mathrm{pp}$. In: Accurate and efficient use of nutrients on farms. Eds. Currie, L.D.; Christensen. C.L. http:// flrc.massey.ac.nz/publications.html. Occasional Report No. 26. Fertilizer and Lime Research Centre, Massey University, Palmerston North, New Zealand.

Miller, P.C.H.; Audsley, E.; Richards, I.R. 2009. Costs and effects of uneven spreading of nitrogen fertlisers. $25 \mathrm{pp}$. In: Proceedings of the International Fertiliser Society. No. 659.
Miserque, O.; Pirard, E.; Schenkel, Y.; Mostade, O.; Huyghebaett, B. 2008. Spreading segregation of blended fertilizers: influence of the particles properties. Proceedings of the American Society of Agricultural and Biological Engineers24: 137- 144

Murray, R.I.; Yule I.J.; Gillingham A.G. 2007. Developing variable rate application technology: modelling annual pasture production on hill country. New Zealand Journal of Agriculture. Research 50: 41-52

Piron, E.; Miclet D.; Villette, S. 2010. CEMIB: an innovative bench for spreader eco-design. 9 pages. $I n$ : Proceedings International Conference on Agricultural Engineering, AgEng2010, ClermontFerrand, France.

Søgaard, H.T.; Kierkegaard, P. 1994. Yield reduction resulting from uneven fertilizer distribution. Transactions. of American Society of Agricultural Engineers 37:1749-1752.

Yule, I.J.; Grafton, M.C.E.; Murray, R.I. 2008. Factors affecting the performance of variable rate application technology (VRAT) for aerial topdressing. 10 pages. In: Proceedings of the American Society of Agricutural and Biological Engineers conference, Providence Rhode Island, ASABE Paper 084025.

Yule, I.J.; Grafton, M.C.E. 2010 Factors affecting fertiliser application uniformity. Pages 413420. In: Farming's future: minimizing footprints and maximizing margins. Eds. Currie, L.D.; Christensen,C.L. Occasional Report No. 23. Fertilizer and Lime Research Centre, Massey University, Palmerston North, New Zealand: ISSN 0112-9902.

Yule, I.J. 2011. The effect of fertiliser particle size on spread distribution. 10 pages. In: Adding to the knowledge base for the nutrient manager. Eds. Currie, L.D.; Christensen, C.L. Occasional Report No. 24. Fertilizer and Lime Research Centre, Massey University, Palmerston North, New Zealand: ISSN 0112-9902.

Yule, I.J.; Grafton, M.C.E. 2013. New spreading technologies for improved accuracy and environmental compliance. 13pp. In: Accurate and efficient use of nutrients on farms. Eds. Currie, L.D.; Christensen, C.L. http://flrc.massey.ac.nz/ publications.html. Occasional Report No. 26. Fertilizer and Lime Research Centre, Massey University, Palmerston North, New Zealand.

Zhang, B.; Valentine, I.; Kemp, P.D. 2004. Modelling hill pasture production: a decision tree approach. Proceedings of the New Zealand Grassland Association 66: 197-201. 